\title{
Research progress on adsorption application of attapulgite by visualization analysis in recent 30 years
}

\author{
Mengxin Zhang ${ }^{1, \mathrm{a} 1 \mathrm{st}}$, Hui Huang ${ }^{1, \mathrm{a}^{*} 1 \mathrm{st}}, \mathrm{Ru}^{\mathrm{Li}}{ }^{1, \mathrm{a}}$, Jia Zhang ${ }^{1, \mathrm{a}}$ \\ ${ }^{1}$ School of Materials and Chemical Engineering, Ningbo University of Technology, Ningbo, Zhejiang, China \\ Mengxin Zhang and Hui Huang are co-first author
}

\begin{abstract}
Objective: Objective: attapulgite, as a kind of natural adsorption material with abundant reserves and friendly environment, has been widely concerned by mineral, environment, materials, chemistry and other disciplines.CiteSpace software was used to analyze the literatures about attapulgite adsorption application from 1987 to 2021 in CNKI database. Results: the amount of literature about attapulgite adsorption application showed an increasing trend year by year; The key words were: modification, kinetics, etc.; The core authors were: Shuang Ren, Mengfei Zhang, Bin Shuai etc.; The organization with the largest number of papers was the northwest Key Laboratory of plant nutrition and agricultural environment, Ministry of agriculture. Conclusion: this paper deeply analyzes the development status and current hot spots of attapulgite in the field of adsorption application research, and forecasts the future development trend, in order to promote the efficient utilization of attapulgite and provide reference for the next research.
\end{abstract}

\section{Introduction}

Attapulgite belongs to the sepiolite group of 2: 1 ayered silicate minerals ${ }^{[1]}$. With its superior adsorption performance, wide resource distribution and low price, it is widely used in various fields. With the rapid development of information technology, new technology and new theory have been injected into the discipline research field, and the research object, research method and research content of archival science have changed. Therefore, by drawing the knowledge map of a discipline, we can visually present the research status of a discipline and track the research hotspots in the discipline ${ }^{[2]}$.

\section{Materials and Methods}

\subsection{Literature sources}

With the help of CNKI's advanced search function, We set the keyword as "attapulgite" and the keyword as "adsorption", and limit the publication date to 19872021.(The retrieval date is March 16, 2021 ) For the preliminary screened literature, we manually excluded, deleted news reports, conference papers and other irrelevant articles, and got 528 articles. These articles are exported to the specified folder in the form of Refworks.

\subsection{Data analysis}

Using the software CiteSpace (5.6.R4) to visually analyze the related literature and draw the corresponding knowledge map, which can truly reflect the relationship between the research and development process and the knowledge structure system ${ }^{[3]}$. In the initial interface, we set the analysis focus as keywords, publishing organization and author. The time slice was one year, topN $=50 \%$. The visual images of the software are fine tuned to make it more beautiful. On this basis, the development of attapulgite in the adsorption application field is analyzed in depth.

\section{Results \& Discussion}

\subsection{Statistical analysis of the number of papers}

The number of papers can be used as an important index to measure the development of research in a certain field. With the help of Excel software, this paper draws the curve of the amount of papers published by Attapulgite in recent 30 years, as shown in Figure 1. The overall research began to emerge in 1992, grew rapidly from 2004 to 2008, and has been stable at about 35 since 2009 . 


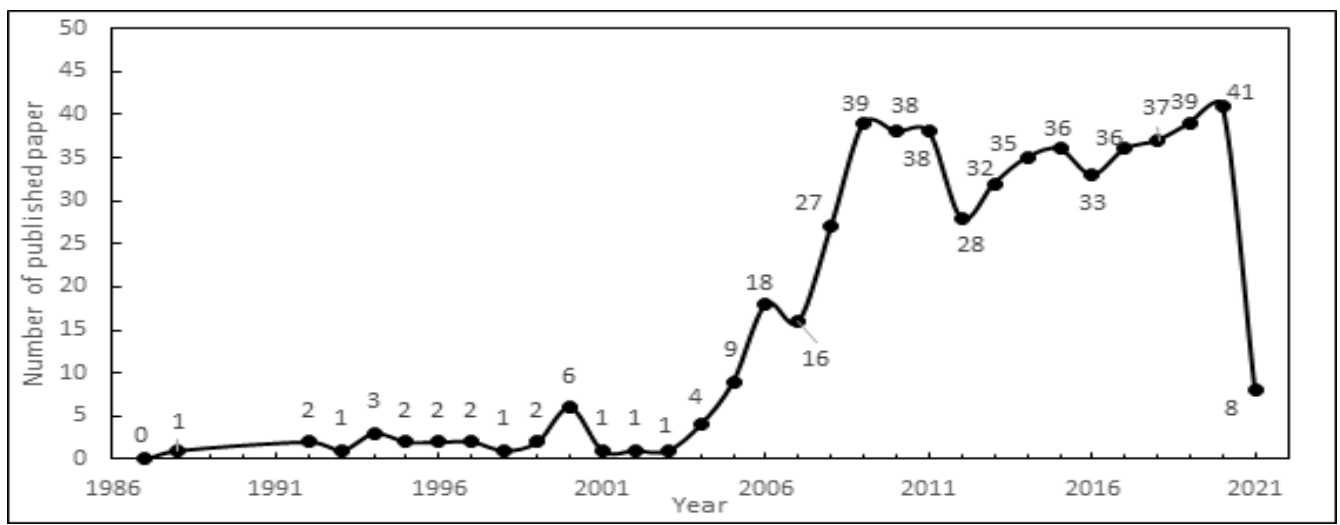

Figure 1 published volume curve of attapulgite adsorption research from 1987 to 2021

\subsection{Research hotspots}

Keywords are the professional terms selected by academically trained scholars, which can represent the theme of the article to a certain extent. Through the frequency and centrality of keywords, we can judge the degree of effect of nodes on the network structure and its changes ${ }^{[4]}$. CiteSpace is used to draw a keyword cooccurrence map, as shown in Figure 2. The cross shape in the map is node, and the size of the node represents the frequency of keywords. There are 111 nodes $(\mathrm{n}=111)$ and 226 connections $(E=226)$ in the graph, and the network density is 0.037 . Because attapulgite and adsorption are limited search terms, the two keywords are hidden manually. The results show that attapulgite, sporption, modification, thermodynamics and so on are highfrequency keywords, which are also research hotspots. The application of attapulgite in the field of high-end adsorbents has been limited due to the presence of associated minerals in raw ore, limited surface negative potential and active adsorption sites ${ }^{[5]}$. How to combine the current high-end technology to make it have more efficient adsorption performance can be a direction of future research.

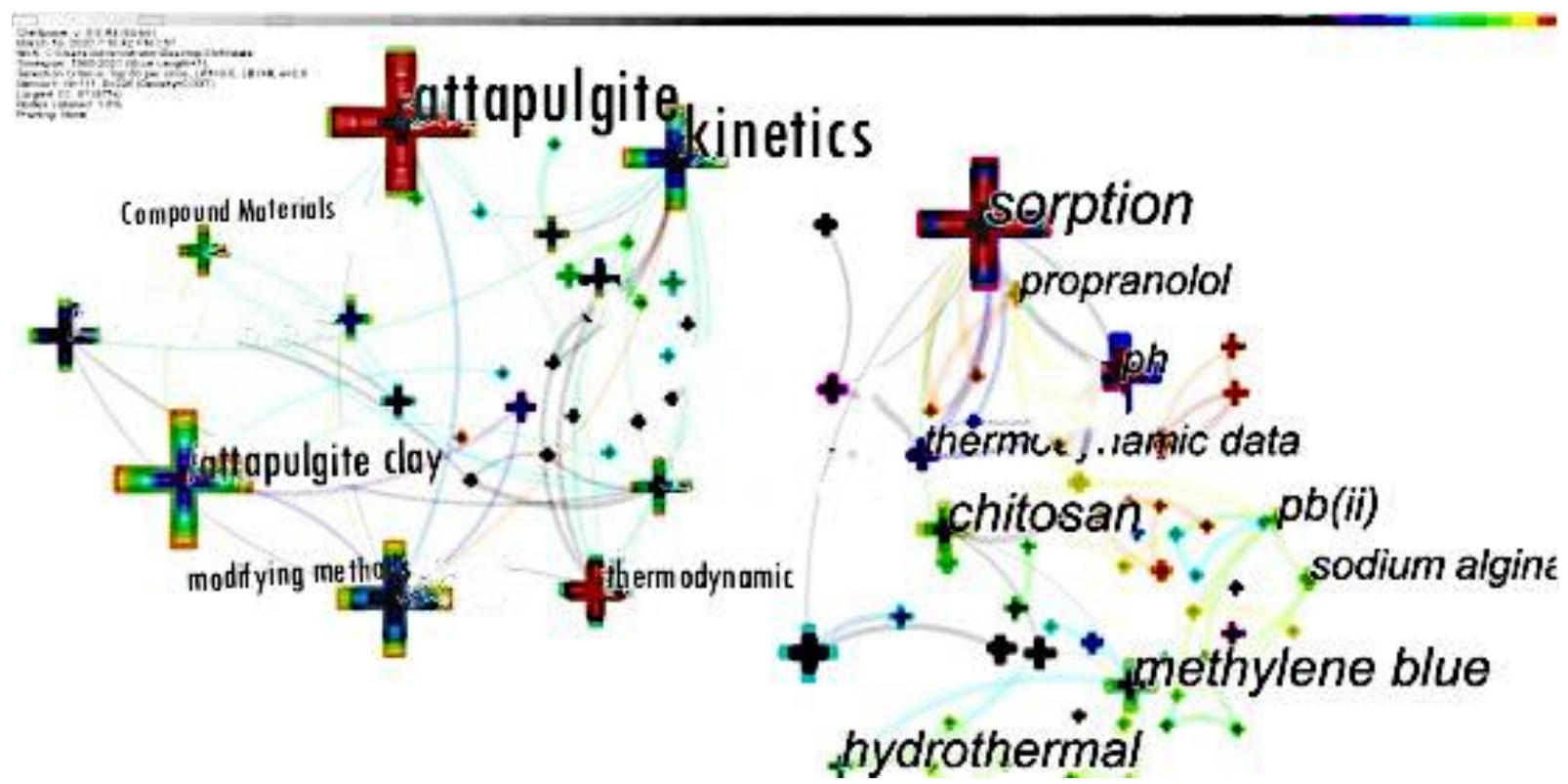

Figure 2 Co occurrence of key words in attapulgite adsorption research from 1960 to 2021

\subsection{Analysis of authors}

Most of the authors are the first to struggle in the front line of scientific research. The visual analysis of authors can directly show the core author group in a certain field, which is conducive to the in-depth study of the field by subsequent scholars. The exchange and cooperation between scientific research scholars can greatly promote the progress of scientific research and the development of science and technology.Table 1 lists the top ten authors in the number of papers published in detail. It can be seen that Shuang Ren and others have started the research on attapulgite as early as 1960 . More than 40 papers have been published in total, almost the sum of the last few scholars. Although Teng Wang started late, he has published 17 papers, ranking fifth Figure 3 shows the cooccurrence of the author, in which the meaning of the logo is the same as that of the keyword map. A total of 501 nodes and 733 connections are shown in the map, with a connection density of 0.0059 . It shows that a cooperative network has been formed between the authors. Small scale cooperation, such as the cooperation group of two or three people, is interspersed like stars. However, the cobweb like cooperative connection diagram only exists in a small 
number of scholars, such as Ren Shuang, Meng Zhaofu, Shuai Bin and so on.But the cooperation is only limited to the cooperation within the team, and the cooperation between teams needs to be strengthened. The cooperation between different teams is conducive to resource sharing, expanding ideas and promoting the further development of attapulgite adsorption technology.
Table 1. Statistic table of top ten authors in number of posts

\begin{tabular}{ccc}
$\begin{array}{c}\text { The number of } \\
\text { papers }\end{array}$ & $\begin{array}{c}\text { Initial } \\
\text { post time }\end{array}$ & Author \\
\hline 49 & 1960 & Shuang Ren \\
48 & 1960 & Zhaofu Meng \\
47 & 1960 & Bin Shuai \\
46 & 1960 & Mengfei Zhang \\
17 & 2008 & Teng Wang \\
16 & 1999 & Aiqin Wang \\
10 & 2003 & Tianhu Chen \\
7 & 2009 & Shuchuan Peng \\
7 & 1996 & Chunxiang Li \\
7 & 1995 & Ping Li \\
\hline
\end{tabular}

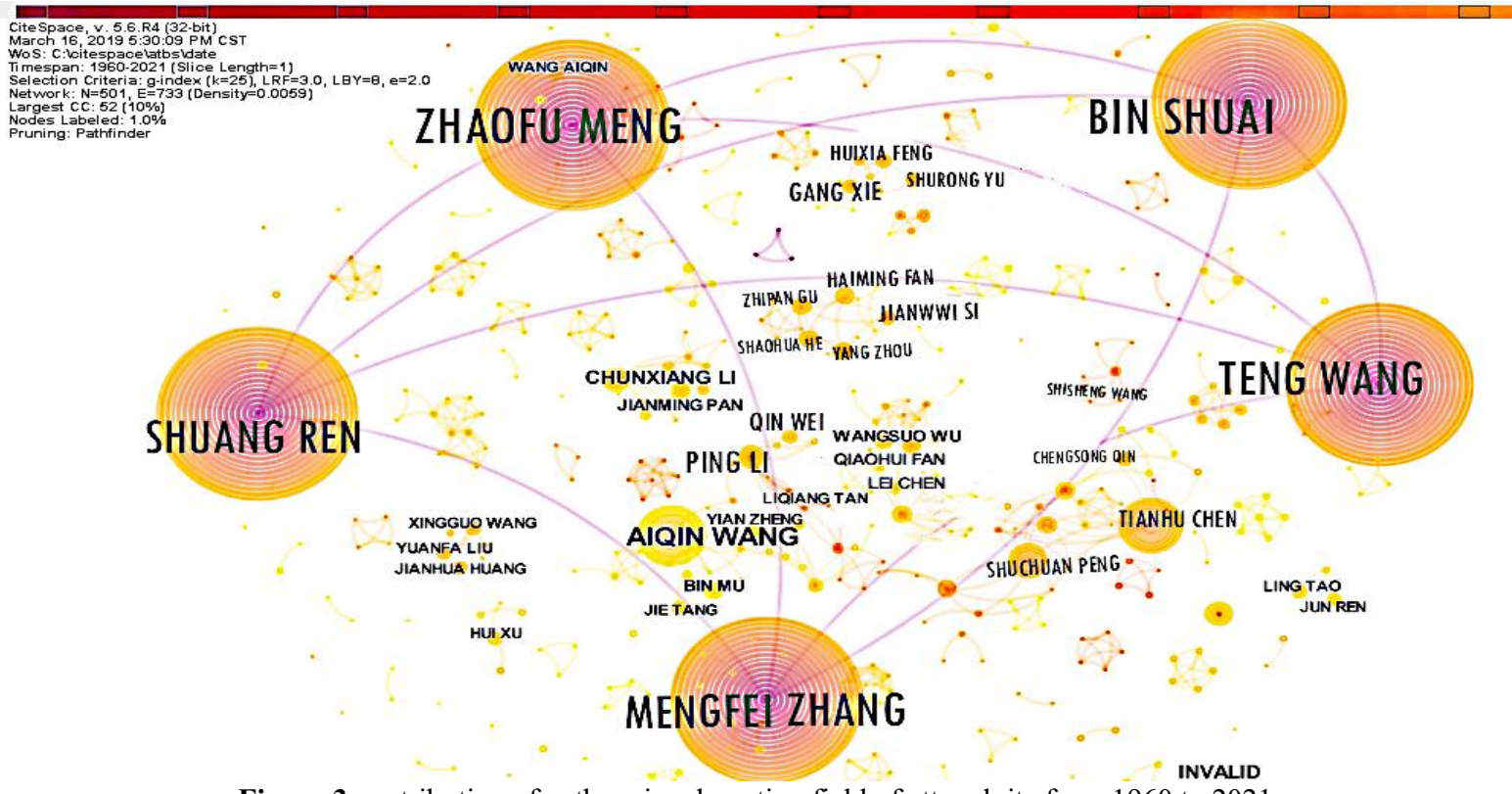

Figure 3 contribution of authors in adsorption field of attapulgite from 1960 to 2021

\subsection{Issuing organization}

Run CiteSpace 5.6.R4 software to generate the knowledge map of research institute cooperation (Figure 4). There are 209 links and 125 nodes in the map, and the node density is 0.0058 , which indicates that the cooperation between research institutions is close. Through the analysis of the output of papers, the backbone of attapulgite adsorption research is mainly concentrated in Colleges and universities. The high-yield research institutions include the northwest Key Laboratory of plant nutrition and agricultural environment of the Ministry of agriculture (55 papers), School of resources and environment of Northwest A \& F University (52 papers), School of petroleum and chemical engineering of Lanzhou University of Technology (19 papers), and resource and environmental engineering of Hefei University of technologyCheng College (14 papers), the above institutions have initially established cooperation networks, and close exchanges among universities are conducive to promoting scientific and deep development of research.At the same time, the research network formed by the University of Chinese Academy of Sciences, Key Laboratory of clay mineral applied research of Gansu Province and center of Xuyi palygorskite applied technology has wide and dense branches and comprehensive coverage, which greatly represents the research status of collaborative experiment in this field. 


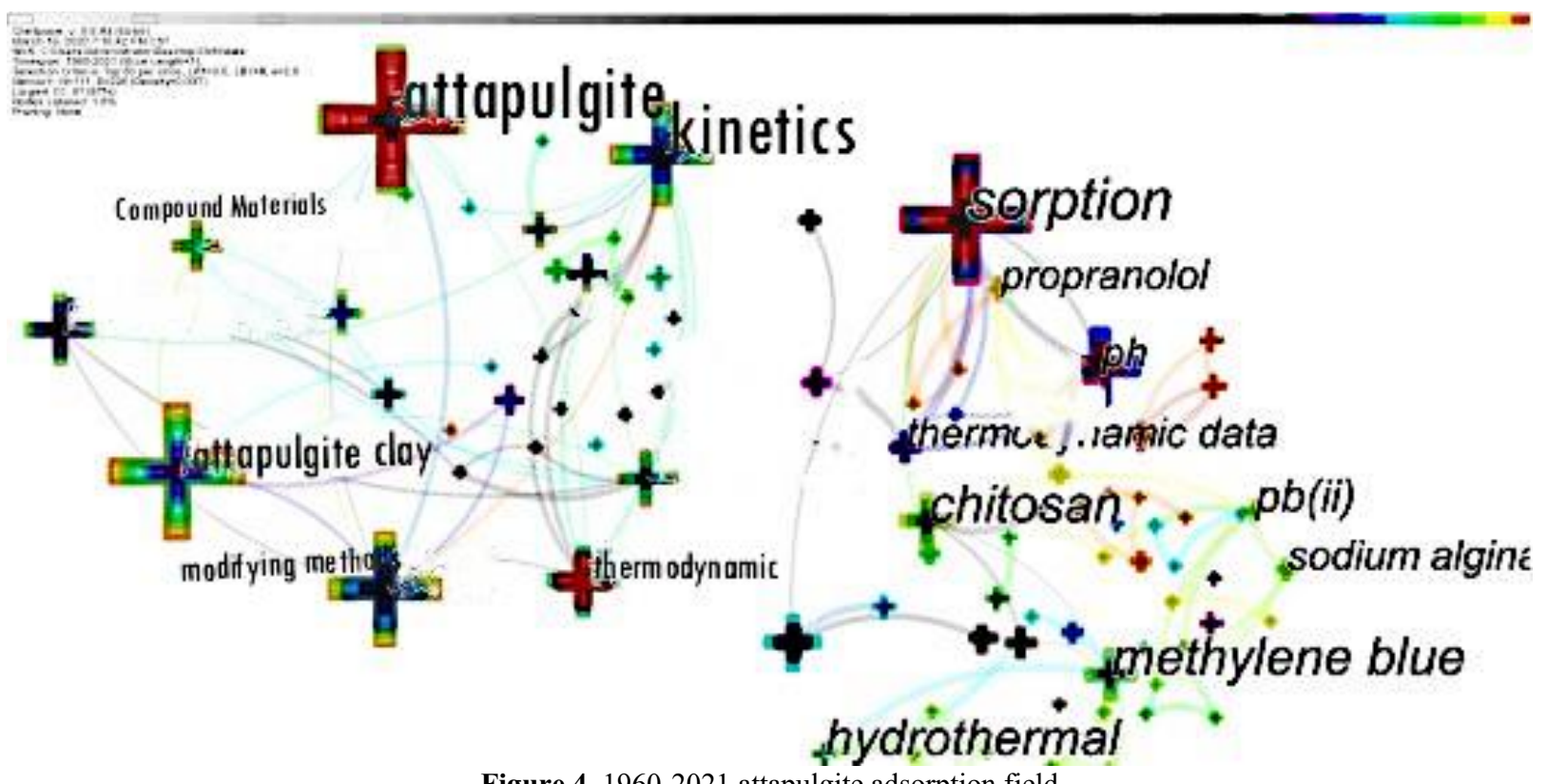

Figure 4 1960-2021 attapulgite adsorption field

\section{Conclusions}

The graph of published papers shows that the research of attapulgite in the field of adsorption is of great value, and the published papers have passed through the initial slow development stage. Now the scientific research achievements of attapulgite in China are showing an increasing trend, but the number of achievements at home and abroad is still insufficient. We expect more researchers to invest and pay attention to it in the future. In recent years, the research focus of attapulgite is mainly modification, composite materials, etc. in the future, we should consider promoting the high-end development of attapulgite application field, continuously improving the added value of products, and boosting the upgrading of attapulgite industrial chain and the sustainable development of the industry.

The core authors of attapulgite are Ren Shuang, Wang Teng, Zhang Mengfei, shuaibin and Meng Zhaofu.However, it is worth noting that the cooperation between the research teams is not close enough, and a good atmosphere of cooperation and competition has not yet formed.We can start with rich and colorful academic exchange activities to strengthen the communication between teams.

Based on the whole, most of the research institutions in the field of attapulgite carry out research in the form of cooperative network. The Key Laboratory of Northwest plant nutrition and agricultural environment of the Ministry of agriculture and the school of resources and environment of Northwest A \& F University have made outstanding contributions as the core forces. The cooperation between the institutions has effectively promoted the research process, and encouraged other research institutions to closely communicate with and promote each other's development.

\section{Acknowledgments}

This work was supported by Student Innovation and Entrepreneurship Training Program of China (202011058005) and the Student Research Program of Ningbo University of Technology (2020034).

\section{References}

1. Zhao, H.H., Song, H.L., Tao X.Y., Chen G.X., Wang A.Q., Chou L.J. (2021) Research progress of layered silicate clay / silicone rubber nanocomposites .Bull. Chi. Cer. Soc., 40 : 493-504.

2. Xiong H.X., Li J.L. (2020) Knowledge mapping analysis of archival research in China based on CSSCI, Arc. Res., 3:16-24.

3. Li, R., Huang, H., Zhang, J., Zhang, M.X. (2021) Research status and hot spot visualization analysis of "gas safety" based on CiteSpace. E3S Web of Conferences, 228.

4. Zhu, Y.P., Wang, X.G., Nie, S.Y., Wang, G.H., Guo Y.D., Li P. (2019) Research progress on Application of clay mineral materials in uranium containing wastewater treatment. Tech. Water Tre., 45: 13-17,29.

5. Dong, W.K., Wang, W.B., Wang, A.Q. (2018) Research progress on Functionalization and Adsorption Application of attapulgite . Poly. Bull., 8: 87-98. 